\title{
The ancient cultural framework of astronomy in Ukraine
}

\author{
Iryna B. Vavilova and Tetyna G. Artemenko \\ Main Astronomical Observatory of the NAS of Ukraine, \\ Akad. Zabolotnogo St., 27, Kyiv MSP 03680 Ukraine \\ email:vavilova@nas.gov.ua tart@mao.kiev.ua
}

\begin{abstract}
We describe and discuss most interesting archaeological findings related to old astronomy in Ukraine. Among them are the mammoth tusk fragments (Gontsy and Kiev-Kirilivska settlements) and the famous Mezin bracelets (Mezin settlement), where possible calendar patterns based on the lunar cycles are engraved with fine accuracy, as well as a possible stellar map on the mammoth shoulder bone (Chocurcha-2 settlement).
\end{abstract}

Keywords. Paleolithic, calendars, Mezin

\section{Paleolithic sites in Ukraine}

During the 19-20 centuries numerous Paleolithic finds were unearthed in the territory of Ukraine. The term 'finds' hereafter means the different artefacts made from mammoth bones and tusks, stone, bird bones, etc., as well as ornaments and patterns on these objects. Some of these finds may constitute evidence about a long history of astronomical culture of our ancestors. Several well-known settlements - Ioudinovo, Timonovka, Elisseevitchi, Suponevo, Mezin, Kiev-Kirilovskaya, Dobranichivka, Gontsy, Mezhirich and others are shown on Fig. 1a. They are dated by ${ }^{14} \mathrm{C}$ between about 27,000 and 12,000 years ago. Such finds as the fragments of mammoth bone huts, various structures and belongings built primarily from the mammoth bones and tusks, are known from ancient settlements throughout Europe but with a main concentration found in the Dnipro river basin of the North-Western Ukraine. Yet one region of Ukraine, the Crimean peninsula, is widely represented by Paleolithic settlements. Among them are Shaitan-Coba, Staroselie, Ak-Kaya, Volchy (Wolf) Grotto, where the primitive families of Neanderthals have lived in the Mustier epoch $(100-40$ millennia BCE).

In this context, the Mezhirich settlement (near Kaniv in the Cherkasy region) has a unique significance for our knowledge on the living conditions and human heritage of the primitive people. This settlement was discovered in 1965 when a farmer began excavating a cellar, almost two meters below ground level, he struck the massive lower jaw of a mammoth with his spade. The dwellings are to be some of the oldest known houses in the world dated back to 15,000 years ago. The roof's support was made up of about three-dozen curved mammoth tusks, some of which were still in their sockets in the skulls during their discovery. The mammoth bones were used for the framework and foundation of these huts when wood was scarce and there were no available caves (Fig. 1b). It has been estimated that the total of bones incorporated in this structure must have belonged to a minimum of ninety-five mammoths. Analysis of the remains allows one to conclude about a variety of activity that occurred: building of long-term dwellings; stone tool manufacture and repair; use of red and yellow ochre pigment in ornaments; use of bone needles in sewing; skinning of fox and weasel, living the complete skeleton intact; cooking of large and small mammal; use of bones as fuel in the fires; some 
possible use of berries and seeds. The food remains include mammoth, rhinoceros, horse, bison, hare and birds (see monograph by Pidoplichko (1998)). Among other interesting finds were: a possible map, engravied on a mammoth tusk which could be interpreted to show a river with dwellings along a river (James \& Thorpe 1994), and the earliest known musical instruments made from decorated mammoth bones with a mammoth skull used as a kind of drum-like instrument (Abramova 1962).

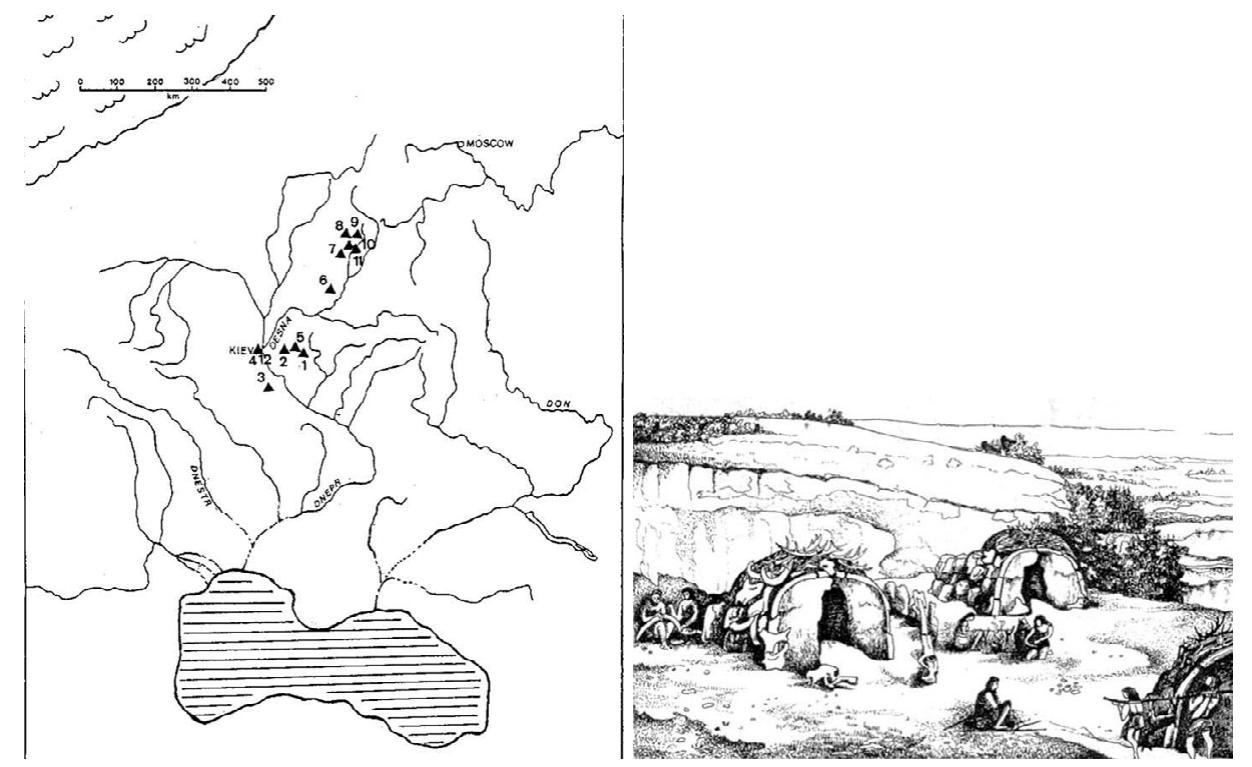

Figure 1. (Left) Paleolithic settlements at the territory of Ukraine: (1) Gontsy, (2) Dobranichivka, (3) Mezhirich, (4) Kiev-Kirilivska, (5) Semenivka, (6) Mezin, (7) Ioudinovo, (8) Elisseevitchi, (9) Timonovka, (10) Suponevo, (11) Chulatovo, (12) Fastiv (Iakovleva 2005); (Right)"Mezin scene": two huts with tusks (Jelinek 1975).

\section{Possible astronomical calendars and stellar maps}

The interpretation of possible 'astronomical' archaeological finds related to the uppermiddle Paleolithic times (35-8 millennia BCE) is very difficult. The first scientific methodological approaches to establish some interrelation between lunar cycles and rhythmic grooves and pits on various finds from the Paleolithic settlements were proposed in 1960s. First of all, Marshak (1964), and later on in his monograph (Marshak 1972), initiated a 'revolution' of prehistoric archeology as concerns with 'the lunar notation on upper Paleolithic remains'. He was the first who has pointed out our attention to the works of E.A. Lartet, the famous French archeologist and geologist. Yet in the 19 century, Lartet argued in favor of that the geometrical 'patterns' formed by notches, dots and other regular symbols could be used by primitive people to register a time duration between periodical natural processes. After studying numerous stones, bones, etc., Marshak concluded that such patterns possibly are calendars based on lunar cycles. This idea was developed by Vértes (1965). Concerning the Paleolithic finds in Ukraine a high knowledge/art of primitive people and interpretations of such symbols as the astronomical calendars of daily life were confirmed in many works (Frolov 1971; Shovkoplyas 1965; Okladnikov 1967; Chernysh 1979). Numerous evidences of cultural-ethnical differences between neighbouring groups of primitive people confirm that they have belonged already to the modern 
anthropological Homo sapiens type. The more we analyse a diversity of archeological Paleolithic finds, the more we are convinced of that the rudiments of astronomical observations and calendars were the logical links in series of evidences of a possible 'Paleolithic primitive pre-scientific knowledge'.

As a confirmation let us describe and discuss a few unique finds unearthed in Paleolithic settlements in Ukraine. In 1871, one of the most ancient settlements (dated 15 millennium $\mathrm{BCE}$ ) was discovered on the right bank of Uday river near the vollage of Gontsy in Poltava region by F.L. Kaminsky, teacher and amateur archaeologist. Gontsy became the first upper Paleolithic settlement, from which archeological research began in Eastern Europe. In 1873, 1914-1915, 1935, 1977-79 and from 1993 it was studied in detail. Among the amazing finds were two single objects dating back 16-12 millennia BCE, which are unique not only as the examples of a primitive art (see, for details Abramova 1962).

The well-saved mammoth's tusk fragment covered by an intricate pattern grooving with a fine accuracy is the most interesting for us. One can see (Fig. 2a) that in the centre of a tusk fragment there is a thin curved line, from which for both sides the alternating lines of different length depart at the right angles, one longer and several very short afterwards, again longer and several very short after, etc., in total 32 long and 78 short lines. Yet Boriskovsky in 1953, one of the first researchers of this pattern, noted that this decorative pattern has a certain sense. Later on it was interpreted as a table of lunar phase observations during four lunar months (see also Zosimovich 1992), where $\mathrm{V}$-vivid line is the axis of time and the strokes of different length mark the phases of the Moon. The Moon going to harm is marked as a double stroke; first and the last fourth, and also new Moon are marked as long lines. One can see from the positions of strokes that for the first lunar month it is one stroke turned outside; the second lunar month is marked by two strokes; the image of the third month is damaged; the fourth lunar month has four strokes turned outside. It was a fantastical example for the 'prearithmetical code' of the Paleolithic astronomical calendar! (Being the part of collection of the Poltava State Historical Museum till the Second World War time this find burned out after a bomb attack).
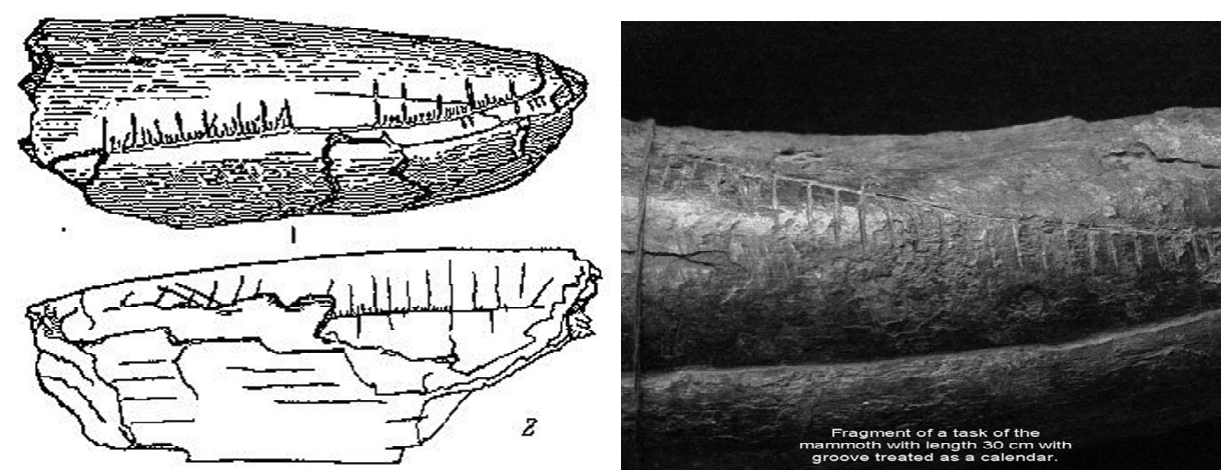

Figure 2. (Left) Sketch of a pattern on the mammoth tusk fragments from the Paleolithic Kiev-Kirilovska settlement (1), and Gontsy settlement (2), dated 15,000 BCE; (Right) Mammoth tusk fragment from the Kiev-Kirilovska settlement with the pattern, which is possibly interpreted as an ancient calendar of lunar phases. National Museum of the History of Ukraine, Kyiv.

Yet one Late-Paleolithic settlement, Kiev-Kirilovska, was unearthed in Kyiv, at the Kyrilivska Street, by the famous Ukrainian scientist V. Khvoyko. In 1893, during the archaeological excavations of the $21 \mathrm{~m}$ deep cultural layer he discovered a well-preserved 
collection of instruments and hand-made goods from mammoth bones, tusks and molars. These items belonged to at least 50 persons of different ages. A bone engraving on a 30 $\mathrm{cm}$-long piece of mammoth tusk represents the head of a long-beaked bird, an animal silhouette identified as a turtle and line ornamentation. Remarkably, one of the tusk pieces with a length of $30 \mathrm{~cm}$ has rough indentations and line ornamentations likely grooved ancient calendar (Fig. 2b). This pattern is very similar to that as on the aforementioned mammoth tusk from the Gontsy settlement.

The remains of another settlement dated of the upper Paleolithic on the right bank of the Desna river near Mezin, Chernigiv region (Fig. 1b) were found casually when digging a hole for a cellar in 1908. The announcement about this discovery was reported immediately by F.K. Volkov at the XIVth Archaeological Meeting in Chernigiv in August 1908. At present, due to the archaeological expeditions of 1930, 1932, 1954-1956, the Mezin Paleolithic settlement is the most studied one in Ukraine.

Among the unique finds later on named as the Mezin art were the mammoth ivory phallic figurines and birds as well as bones painted with red ochre; female statuette carved with double pubic triangle and engraved chevrons; mammoth ivory needle with eye, engraved with chevrons (see, for example Shovkoplyas 1965, for the first detailed prospecting). The most remarkable Mezin art objects are two elaborately created and lavishly ornamented bracelets engraved out of mammoth ivory. These Paleolithic bracelets dated from about 20,000 BCE as Okladnikov wrote are "the authentic masterpieces of bonecarver art, causing a surprise due to that they are executed by the stone instruments, without a lathe, drills, and chisels. A bone material for these decorations had an exceptional aesthetic value. At the same time, neither magic, including magic of numbers, nor cult of ancestors had, on the essence, a direct relation to the rhythmic alternation and to the symmetric position of decorative pattern" (Okladnikov 1967). They have a magnificent design which can be found to this day in the embroidery of Ukrainian costumes. This pattern predates and similar to the famous Greek 'meander' pattern.

The first from these bracelets (Fig. 3a), unearthed in 1912, has the "appearance of the wide and thin bent plate, the external surface of which is covered by the complicated geometrical decorative meander and fir-tree pattern. On the ends of bangle are for three large openings for lacing. Width of plate is $5.3 \mathrm{~cm}$ " (Abramova 1962, Table XXXIV). It may be considered as a coincidence but this artifact may represent a rare example of the
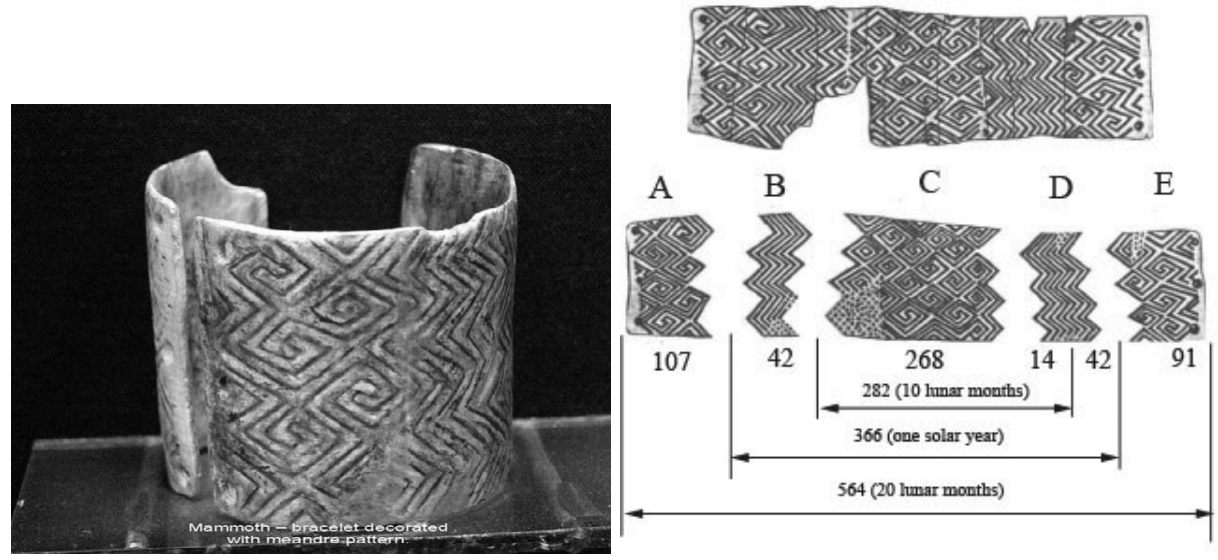

Figure 3. (Left) The wide bracelet from the Mezin Paleolithic settlement, Chernigiv region, Ukraine. National Museum of the History of Ukraine, Kyiv; (Right) Explanation of this ornament as a possible ancient lunar-solar calendar by Frolov (1971). 
most ancient lunar-solar calendar. Binning this pattern as in Fig.3b one can find that "two reiterating meander groups are divided twice by zones of zigzags. Each of zigzags consists of 7 lines. We may select surely 5 zones of pattern: $A, C$, and $E$ in the centre and at the edges of meander zone; $B$ and D zones" (Frolov 1971). This ornament covered by parallel strokes and parted on the areas of zigzags, consists in a total of 564 lines (20 lunar months). It is interesting that a number of lines in the central area and in zigzags are equal to 366 that almost correspond to one solar year. Another important conclusion is that this possible form of ancient calendar is based exactly on the period of 10 lunar months or 280 days.

The second Mezin bracelet, which was discovered in 1956, is a very unique Paleolithic find too (Fig. 4a). It is composing from five joined rings made from the mammoth tusk (length about $19 \mathrm{~cm}$, width about $1 \mathrm{~cm}$ ) and edged with ornamentation. The external surfaces of plates are covered by a fretwork geometrical pattern: rows of fir-trees are directed to the opposite sides and form a clear meander pattern at the junctions from the recurring groups of parallel strokes, which are directed at an angle to the edge of bracelet (Abramova 1962; Shovkoplyas 1965). This ornament can possibly interpreted as a primitive calendar with the fertility and crop symbols. It is known that namely a meander pattern is considered as symbol of fertility. Most groups consist of 14 strokes; there are groups from 13 and 15 strokes. Direction of strokes in two neighboring groups is $90^{\circ}$. Each part of bracelet from 27-29 strokes could be interpreted as a calendar of the lunar months. The changes of direction of strokes at $90^{\circ}$ may reflect that a lunar disc is increasing during the first part of month and decreasing in the second part of month. In other words, the essence of interpretation is as follows (Fig. 4b). Groups from $14( \pm 1)$ strokes, which change its direction periodically exactly after this number, could correspond with the same visibility occurrence, in this case with the increasing lunar disc before the full Moon, and with the decreasing lunar disc before the new Moon during the 28-29 days of the lunar month. Obeying this rhythm, two lunar months are 'written' at the edges of plates. It results that a full number of days in 10 lunar months could be 'written' on all 5 plates of the bracelet (Frolov 1971).

What is important to emphasise that the base of these possible palaeo-astronomical calendars (10 lunar months or 280 days) coincides with a period of the pregnancy for women. Many scientists consider that such a period related to the Moon could be chosen by the primitive people as the obvious unit of measurements of time duration for the longterm observational events. Incidentally, Shovkoplyas (1965), studying a form of ornaments on the both Mezin bracelets in detail, noted that they have specifically female attributes.
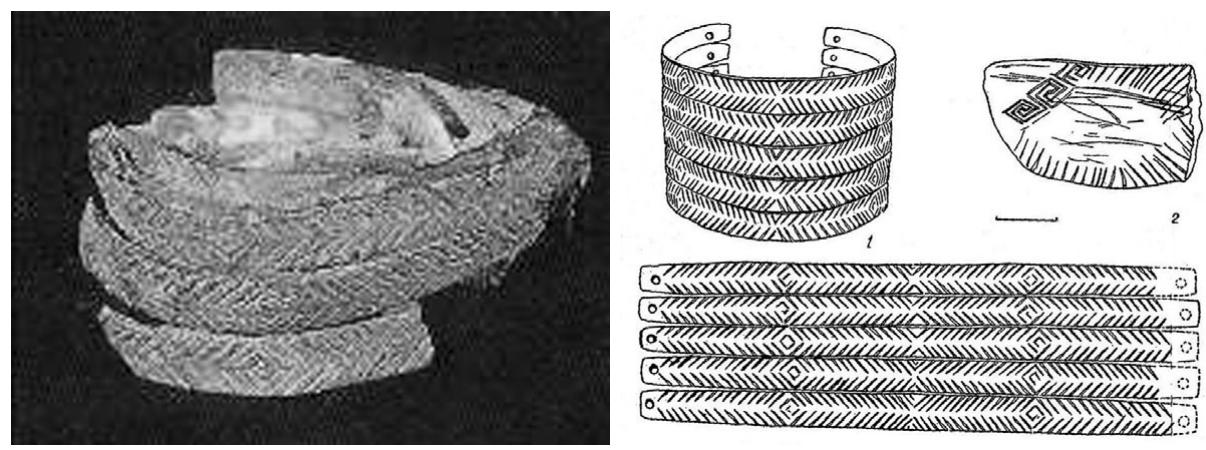

Figure 4. (Left) The bracelet from the Mezin Paleolithic settlement, Chernigiv region, Ukraine. National Museum of the History of Ukraine, Kyiv; (Right) Explanation of this ornament as a possible ancient lunar calendar by Frolov (1971). 
Meanwhile the bracelets from mammoth tusk were found at the Paleolithic settlements in Russia, France, and Belgium, but Mezin bracelets have no analogues in ornamentation. We note also that the geometrical ornamentation of these Paleolithic finds, which reaches a maximal complication at the Mezin bracelets, in particular in the wide bracelet (Fig. 3), is not causal. These finds are so perfect that they required elaborate inputs, skills, time and mastery in comparison with other finds revealed at these settlements. Without doubt they have concentrated valuable crumbs of ancient knowledge about rhythms of Cosmos. Such ornaments may testify that humans of the upper Paleolithic may had the concept of long-term counting of the lunar phases. if so, a complicated lunar mythology was surely engendered in these Paleolithic times.

In the 1970s the new settlement Chocurcha-Grotto-2 in Crimea (near Simferopol, Small Salgir river valley), was discovered by A. Stolbunov, a teacher who studied a local lore, and by Prof. O.N. Bader. Besides Chocurcha-Grotto-1, which is described from the 1920s in many works due to the famous petroglyphs (Sun-like images with rays, mammoth and fish), in the second grotto a unique collection of miniatures was found with images of 'man-bird', 'man-bear', 'man-mammoth'. Among the finds a mammoth shoulder bone with patterns formed by numerous spotted images, dated to 30,000 BCE. In 1979, Prof. Chernov identified these images with the well-known stellar maps by Mikhailov. He concluded that this Paleolithic map of heaven, possibly the oldest one we know, contains 102 stars from 17 constellations of the Northern and Southern sky. The boundaries of the Southern sky region at this map are $\alpha=12^{h}-21^{h}$, and from $\delta=-40^{\circ}$ (see V. Mitrokhin, http://www.proza.ru/2006/12/21-214, in Russian).

\section{Conclusion}

We have described some very interesting Paleolithic finds possibly related to ancient astronomy from the Gontsy, Kiev-Kirilovska, Mesin and Chocurcha-Grotto-2 settlements in Ukraine. This study will be continued to classify all ancient astronomical objects and to create an atlas of Ukraine's astronomical heritage.

\section{Acknowledgements}

The authors express their gratitude to Prof. Ya.S. Yatskiv, Prof. Ya.V. Pavlenko, and Dr. Iryna D. Zosimovich for helpful discussions.

\section{References}

Abramova, Z.A. 1962, in Archeology of the USSR, B.A. Rybakov (ed) (Moscow: Akademiya Nauk SSSR), p. 5

Chernysh, O.P. 1979, Visnyk of the Academy of Sciences of the URSR, 8, 46

Frolov, B.A. 1971, Priroda, 8, 96

Iakovleva, L. 2005, Archeometriai Muhely, 4, 26

James, P. \& Thorpe, N. 1994, Ancient Inventions (New York: Ballantine Books)

Jelinek, J. 1975, The Pictorial Encyclopedia of The Evolution of Man (London: Hamlyn)

Marshak, A. 1964, Science, 146, 743

Marshak, A. 1972, The Roots of Civilization (New York: McGraw-Hill)

Okladnikov, A.P. 1967, The Dawn of Art (Leningrad: Iskusstvo)

Pidoplichko, I.G. 1998, Upper Palaeolithic Dwellings of Mammoth Bones in the Ukraine: KievKirillovski, Gontsy, Dobranichevka, Mezin and Mezhirich (Oxford: BAR IS 712)

Shovkoplyas, I.G. 1965, Mezynska settlement (Kyiv: Naukova dumka)

Vértes, L. 1965, Science, 149, 855

Zosimovich, I.D. 1992, in Reviews on History of the Domestic Astronomy, (Kyiv: Naukova dumka), p. 13 